Andrea Padoan, Renata D’Incà, Maria Luisa Scapellato, Rudi De Bastiani, Roberta Caccaro, Claudia Mescoli, Stefania Moz, Dania Bozzato, Carlo-Federico Zambon, Greta Lorenzon, Massimo Rugge, Mario Plebani and Daniela Basso*

\title{
Improving IBD diagnosis and monitoring by understanding preanalytical, analytical and biological fecal calprotectin variability
}

https://doi.org/10.1515/cclm-2018-0134

Received February 5, 2018; accepted April 3, 2018; previously published online May 5, 2018

\section{Abstract}

Background: The appropriate clinical use of fecal calprotectin (fCal) might be compromised by incomplete harmonization between assays and within- and between-subjects variability. Our aim was to investigate the analytical and biological variability of fCal in order to provide tools for interpreting fCal in the clinical setting.

Methods: Experiments were conducted to investigate the effects of temperature and storage time on fCal. Thirty-nine controls were enrolled to verify biological variability, and a case-control study was conducted on 134 controls and 110 IBD patients to compare the clinical effectiveness of three different fCal assays: ELISA, CLIA and turbidimetry. Results: A 12\% decline in fCal levels was observed within $24 \mathrm{~h}$ following stool collection irrespective of storage temperature. Samples were unstable following a longer storage time interval at room temperature. Within- and betweensubjects fCal biological variability, at 31\% and 72\% respectively, resulted in a reference change value (RCV) in the region of $100 \%$. fCal sensitivity in distinguishing between

\footnotetext{
*Corresponding author: Daniela Basso, MD, Department of Medicine - DIMED, University of Padova, Via Giustiniani 2, 35128 Padova, Italy, Phone: +390498212801, Fax: +390498211981, E-mail: daniela.basso@unipd.it

Andrea Padoan, Claudia Mescoli, Stefania Moz, Dania Bozzato, Massimo Rugge and Mario Plebani: Department of Medicine DIMED, University of Padova, Padova, Italy. http://orcid.org/00000003-1284-7885 (A. Padoan); http://orcid.org/0000-0002-02701711 (M. Plebani)

Renata D'Incà, Roberta Caccaro and Greta Lorenzon: Division of Gastroenterology, University Hospital, Padova, Italy

Maria Luisa Scapellato: Department of Cardiologic, Thoracic and Vascular Sciences, Preventive Medicine and Risk Assessment Unit, University Hospital of Padova, Padova, Italy

Rudi De Bastiani: Italian Association for Gastroenterology in Primary Care (GICA-CP), Feltre, Italy

Carlo-Federico Zambon: Department of Biomedical Sciences BIOMED, University of Padova, Padova, Italy
}

controls and IBD patients is satisfactory $(68 \%)$, and the specificity high $(93 \%)$ among young ( $<65$ years), but not among older ( $\geq 65$ years) subjects (ROC area: 0.584 ; $95 \%$ CI: 0.399-0.769). Among the young, assays have different optimal thresholds $(120 \mu \mathrm{g} / \mathrm{g}$ for ELISA, $50 \mu \mathrm{g} / \mathrm{g}$ for CLIA and $100 \mu \mathrm{g} / \mathrm{g}$ for turbidimetry).

Conclusions: We recommend a standardized preanalytical protocol for fCal, avoiding storage at room temperature for more than $24 \mathrm{~h}$. Different cutoffs are recommended for different fCal assays. In monitoring, the difference between two consecutive measurements appears clinically significant when higher than $100 \%$, the fCal biological variability-derived RCV.

Keywords: biological variability; calprotectin; Crohn's disease; inflammatory bowel diseases; ulcerative colitis.

\section{Introduction}

The widespread use of fecal calprotectin (fCal) determination in clinical practice has been challenged in the last few decades by a more effective diagnostic workup for patients with inflammatory bowel diseases (IBD), which comprise Crohn's disease (CD), ulcerative colitis (UC) and a subset of conditions with clinical, endoscopic, radiological and pathological phenotypes at the crossroads between $\mathrm{CD}$ and UC, the so-called "IBD, type unclassified" [1]. Intestinal inflammation is the common determinant of IBD, UC being characterized by diffuse mucosal inflammation of the colon-rectum, whereas CD can affect any part of the gastrointestinal tract, transmural inflammation potentially causing stenosis, perforation and fistulae. The administration of aminosalicylates, corticosteroids, thiopurines, methotrexate and anti-TNF can be effective in treating IBD, which typically occur in young subjects and tend to become chronic, with alternating flare-ups and remissions. Laboratory medicine can help clinicians to (1) differentiate between IBD and irritable bowel syndrome and make a diagnosis, (2) define the type of IBD (UC or $\mathrm{CD}$ ) and (3) monitor IBD to promptly detect flare-ups and 
predict response to therapy [2, 3]. Although not specific for IBD, blood inflammatory biomarkers, such as C-reactive protein, can be of value in the assessment of acute phases. The sensitivity of markers in defining the IBD type, such as UC-associated pANCA and CD-associated ASCA, is considered satisfactory but does not exceed $60 \%$ [2].

The two most extensively studied fecal biomarkers of IBD, fCal (an S100A8/S100A9 calcium binding heterodimer) and lactoferrin (an iron binding protein), have antimicrobial properties, are released by inflammatory cells infiltrating the gastrointestinal mucosa and are resistant to proteolysis, which renders their measurement in stool a reliable tracer of intestinal inflammation, although $\mathrm{fCal}$ is reported to be more sensitive and specific than lactoferrin $[4,5]$. However, qualitative fCal assays are not clinically useful, with the decision making being based on a quantitative result $(\mu \mathrm{g} / \mathrm{g})$. Different thresholds allow different clinical questions to be addressed in different settings: values below $50 \mu \mathrm{g} / \mathrm{g}$ in adults and $100 \mu \mathrm{g} / \mathrm{g}$ in children rule out intestinal inflammation with a high negative predictive value ( $81 \%$ in primary and $98 \%$ in secondary care), whereas values above $150 \mu \mathrm{g} / \mathrm{g}$ in adults and $300 \mu \mathrm{g} / \mathrm{g}$ in children may be highly sensitive in predicting IBD (>90\%) [6-8]. In patients with a confirmed diagnosis of IBD, values above $250 \mu \mathrm{g} / \mathrm{g}$ in adults and $500 \mu \mathrm{g} / \mathrm{g}$ in children are useful in predicting disease activity, risk of relapse and response to therapy [6, 9-12].

From a clinical laboratory perspective, both the preanalytical (stool storage, weighting and sampling with dedicated devices) and the analytical (ELISA, chemiluminescence [CLIA] or turbidimetric assays) phases must be verified. This appears more relevant now than ever because UK NEQAS, the well-known organizer of external quality assessment (EQA) schemes that started fCal EQA after a pilot study in 2013 [13], discontinued its use outside the British Isles in April 2016 in response to the evidence that specimens deteriorated rapidly during prolonged transport, a finding that contradicted previous claims that fCal was stable at room temperature (RT) for at least 1 week, thus reigniting the debate regarding optimal sample storage conditions for reliable results [14, 15]. Moreover, the reproducibility of sampling and weighting has yet to be addressed because only a few non-systematic studies are available on this topic $[13,14,16]$. The total variability of a given laboratory test depends not only on preanalytical and analytical but also on biological variability. However, few authors have reported on fCal biological variability by evaluating minimal case series sets [14, 16-18]. A reliable definition of biological variability appears to be extremely relevant for fCal, in view of its role in monitoring IBD patients, and is of crucial importance in establishing the reference change value (RCV), and ascertaining whether the difference between two consecutive fCal results is of clinical significance [19].

Currently marketed fCal assays are based on three main technologies, ELISA, CLIA and turbidimetry, but it has yet to be established whether the different assays have comparable clinical sensitivities and specificities and share the same reference intervals and decision limits. If this is not the case, it is important to establish whether the necessary performances can be attained and, if so, how [6, 13, 20, 21].

The aim of the present study was to investigate the preanalytical, analytical and clinical factors with a potential effect on fCal. We identified the best preanalytical sample processing step, defined fCal biological variability, and verified whether there are differences between the clinical utility of fCal results obtained with different assays (ELISA, CLIA and turbidimetry) in diagnosing IBD.

\section{Materials and methods}

\section{Preanalytical stability}

To assess the preanalytical stability of fCal, 7 subjects ( $1 \mathrm{M}, 6 \mathrm{~F}$, age range $25-75$ years) without and 14 subjects (6 M, $8 \mathrm{~F}$, age range 1870 years) with IBD were enrolled. A fresh stool sample was obtained from each subject. Within $2 \mathrm{~h}$ of collection, each stool was sampled for fCal assay using the stool sample application system (Immundiagnostik AG, Bensheim, Germany) and immediately frozen at $-20^{\circ} \mathrm{C}$ as recommended by the manufacturer (reference, time 0). Each of the remaining stool samples were split into 16 aliquots, 6 of which were kept at RT ( $\mathrm{n}=3$ aliquots) or refrigerated (Cold, $\mathrm{n}=3$ aliquots) for 1, 4 and 7 days (short-term storage), respectively. Of the remaining 10 aliquots, five were immediately frozen at $-20^{\circ} \mathrm{C}$ and five at $-80^{\circ} \mathrm{C}$ and stored at their respective temperatures for 1, 2, 4, 8 and 12 weeks before analysis (long-term storage). At the end of the established storage times (i.e. after 1, 4 and 7 days at RT or at Cold, and after 1, 2, 4, 8 and 12 weeks at $-20^{\circ} \mathrm{C}$ and $-80^{\circ} \mathrm{C}$ ), fecal aliquots were treated as the reference. All extracts were stored at $-20^{\circ} \mathrm{C}$ for no more than 9 days before analysis (IDK Calprotectin ELISA, Immundiagnostik AG, Bensheim, Germany). Short-term storage extracts from the same subject were analyzed in the same analytical batch. For long-term storage, aliquots from the same subject stored at $-20^{\circ} \mathrm{C}$ and $-80^{\circ} \mathrm{C}$ were analyzed in the same analytical batch.

\section{Analytical fCal precision and methods comparison}

A comparative study was made of three fCal assays: ELISA (IDK Calprotectin ELISA, Immundiagnostik AG, Bensheim, Germany) automated on DSX ${ }^{\circledast}$ (Dynex Technology, Denkendorf, Germany), CLIA (QUANTA Flash ${ }^{\circledR}$, INOVA Diagnostics, San Diego, CA, USA) automated on Bio-Flash (INOVA Diagnostics, San Diego, CA, USA) and turbidimetry (Bühlmann $\mathrm{fCAL}^{\circledR}$ turbo, Schönenbuch, Switzerland) automated on c8000 Abbott Architect (Abbott S.r.l., Roma, Italy). Following the 
standardized protocol CLSI EP15-A3 [22], to estimate precision, three fecal samples with low, intermediate and high fCal values were identified. From each stool sample, simultaneously, 25 extracts were prepared using the Stool sample application system (Immundiagnostik AG, Bensheim, Germany) for the ELISA assay, 25 using the Fecal collection device (INOVA Diagnostics, San Diego, CA, USA) for CLIA and 25 using the CALEX Cap Device (Bühlmann, Schönenbuch, Switzerland) for the turbidimetric assay, for a total of 75 extracts/sample. All extracts, which had been immediately frozen at $-20^{\circ} \mathrm{C}$ for no more than 10 days, were analyzed in batches of five replicates in a single run for a total of five runs performed on different days. The extracts were analyzed in parallel using the three methods. In order to compare methods, fCal was assayed in all collected stool samples from patients and controls $(n=244)$ simultaneously with the three different assays.

\section{Patients and controls}

Patients (cases) from the Gastroenterological Unit of the UniversityHospital of Padova with histologically confirmed IBD were enrolled for the present case-control study; the control group comprised outpatients registered with local General Practitioners and employees at the University-Hospital of Padova already included in the standard occupational program, who had neither intestinal symptoms or a history of intestinal disease. These subjects were continually monitored for their health status by medical staff and underwent regular objective clinical examinations. From September 2016 to July 2017, we enrolled a series of 110 consecutive IBD patients ( $65 \mathrm{M}, 45 \mathrm{~F}$, age range 17-83 years), including 73 patients with Crohn's disease (CD) and 37 patients with ulcerative colitis (UC), and 134 controls ( $85 \mathrm{M}$, $49 \mathrm{~F}$, age range $20-86$ years), including 80 employees and 54 outpatients. Fecal samples from the first bowel movement of the day, obtained from all cases and controls at enrolment, were refrigerated up to $4 \mathrm{~h}$ before being delivered to the laboratory, where they were immediately frozen to $-20^{\circ} \mathrm{C}$ and maintained at that temperature for no more than 3 months, until fCal analysis. A series of samples was obtained from 39/134 controls in order to estimate fCal biological variability. At least two stool samples were collected from two independent bowel movements; the time interval between collections was 1-2 weeks. Seven subjects provided two samples from one of the two bowel movements, whereas 20 subjects provided two replicated samples from both bowel movements.

\section{Ethical considerations}

Approval for the study was obtained from the local Ethics Committee (Prot. 3756/AO/16), and fully informed consent was obtained in writing from all cases and controls.

\section{Statistical analysis}

The statistical analysis of data (Kruskal-Wallis test, mixed model longitudinal analysis, ROC curve analysis, Youden index) was made using Stata v 13.1 (StataCorp, College Station, TX, USA), MedCalc v 18 (Ostend, Belgium) and SAS 9.2 (SAS Institute Inc., Cary, NC, USA). Intra- and interindividual biological variations were assessed using Nested ANOVA according to Fraser et al. [23]. Methods were compared using Passing-Bablok regression. Repeatability and within-laboratory precision were calculated with ANOVA.

\section{Results}

\section{Preanalytical fCal stability}

Subjects with $(n=14 / 21)$ or without $(n=7 / 21)$ a diagnosis of IBD were enrolled to verify the effect of stool storage on fCal results. The reference fCal values (TO, stool extracts within $2 \mathrm{~h}$ from collection) of patients with IBD (median $=325 \mu \mathrm{g} / \mathrm{g}$, IQR $=123-545 \mu \mathrm{g} / \mathrm{g}$ ) were significantly higher than those observed in subjects without a diagnosis of IBD (Controls; median $=59 \mu \mathrm{g} / \mathrm{g}$; IQR $=40-97 \mu \mathrm{g} / \mathrm{g}$; Kruskal-Wallis test: $\left.\chi^{2}=56.6, \mathrm{p}<0.0001\right)$. The percentage variations of fCal with respect to the reference value after short- and long-term storage of stools at different temperatures were calculated; mean values with standard errors in the whole population studied are shown in Figure 1. To verify the effects of multiple conditions (different storage temperatures) on repeated measurements (time results), statistical analysis of data was made by mixed model longitudinal analysis (Supplementary Table 1). This analysis showed that a fCal reduction occurred in stool stored at both RT and at $4^{\circ} \mathrm{C}$ for up to 4 and 7 days with respect to day 0 , being the regression coefficients statistically significant. However, RT with respect to $4^{\circ} \mathrm{C}$ caused a more pronounced fCal reduction, being the difference between day 7 and day 1 significant for RT $(\mathrm{p}=0.004)$ not for $4{ }^{\circ} \mathrm{C}$ $(p=0.549)$. This pattern was similar for stool samples obtained from controls and IBD (Supplementary Table 1). Stool freezing did not preserve the initial fCal reduction, which was maintained at $20 \%$ after 1 week at both $-20^{\circ} \mathrm{C}$ and $-80^{\circ} \mathrm{C}$. This decrease was similar that observed in the same samples stored for the same period of time at $4{ }^{\circ} \mathrm{C}$ (Kruskal-Wallis test: $\chi^{2}=0.615, \mathrm{p}=0.893$ ). Intriguingly, the fCal results after long-term storage at $-20^{\circ} \mathrm{C}$ were comparable to those found at $-80^{\circ} \mathrm{C}$ (Kruskal-Wallis test: $\chi^{2}=0.001, \mathrm{p}=0.969$ at 1 month; $\chi^{2}=0.008, \mathrm{p}=0.928$ for 2 months; $\chi^{2}=0.228, \mathrm{p}=0.633$ for 3 months). Supplementary Table 2 reports the results obtained with mixed model longitudinal analysis.

\section{Analytical fCal precision and methods comparison}

The analytical performances of standard ELISA were compared with those of one emerging CLIA and one emerging 

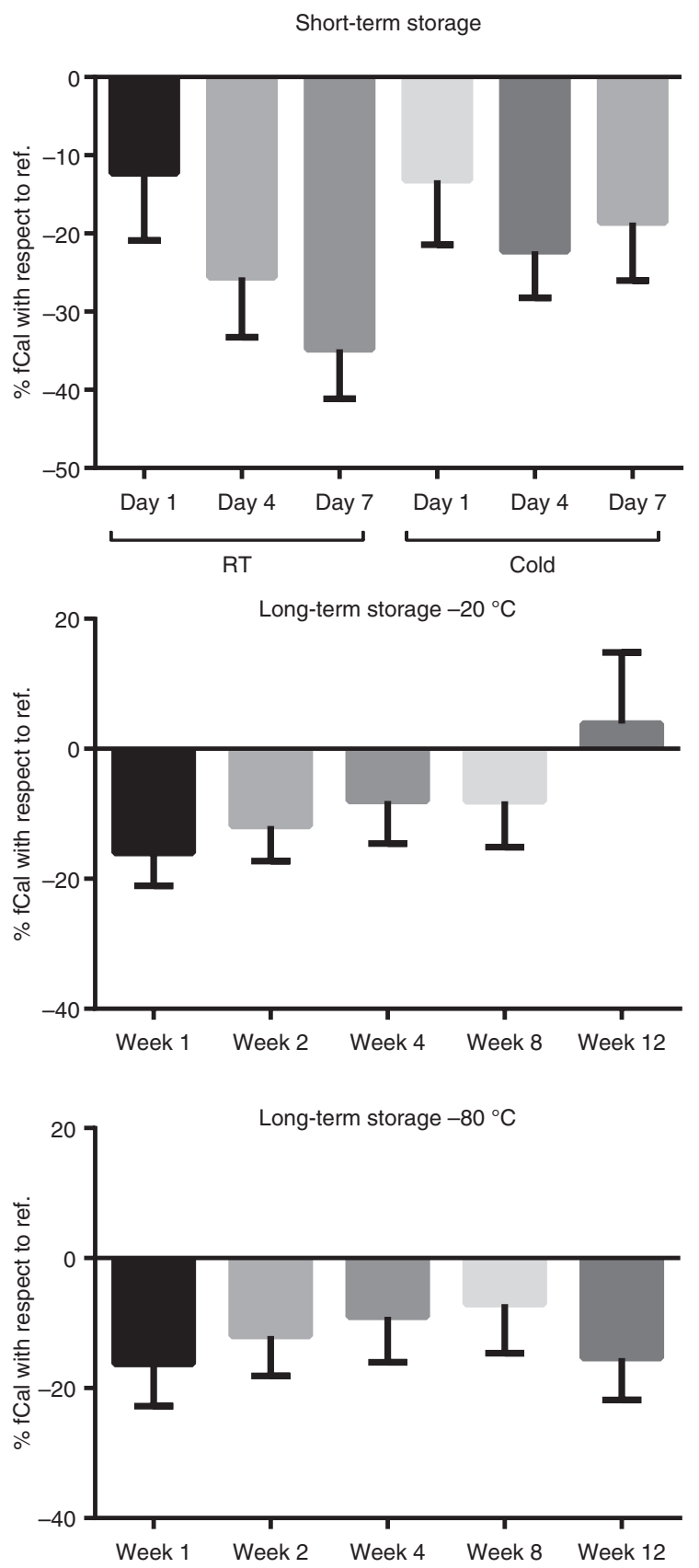

Figure 1: Preanalytical fecal calprotectin (fCal) time and temperature-dependent variability.

fCal was assayed in stools from 14 IBD patients and 7 healthy controls within $2 \mathrm{~h}$ from collection (reference value, ref). The percentage variations of $\mathrm{fCal}$ with respect to ref. after short-term $(1,4$ and 7 days) and long-term (1, 2, 4, 8 and 12 weeks) storage at different temperatures were calculated for each sample. Columns represent mean values and bars standard errors from the whole $(n=21)$ studied samples. RT, room temperature; cold $=4^{\circ} \mathrm{C}$.

turbidimetric fCal assay. The ELISA assay is based on a two-site sandwich technique with two specific anti-calprotectin monoclonal antibodies. The CLIA is a sandwich immunoassay based on calprotectin capture by a specific antibody coated to paramagnetic beads followed, after washing, by the addition of the isoluminol-conjugated second anti-calprotectin antibody. The light produced from the luminescent reaction, measured as relative light units (RLU), is proportional to the amount of calprotectin. The turbidimetric assay is a particle enhanced turbidimetric immunoassay (PETIA) that uses polystyrene nanoparticles coated with anti-calprotectin antibodies. Calprotectin mediates immunoparticles agglutination, which enhances sample turbidity that can be measured by light absorbance. Absorbance is correlated with calprotectin-immunoparticle complex formation that is proportional to calprotectin concentration. Differently from the ELISA assay, CLIA and PETIA systems utilize predefined lot specific master curves for instrumental calibration.

Three fecal samples with concentrations in the low, intermediate and high range were selected from the large set of samples used for methods comparisons (see below). Table 1 reports the results for repeatability and withinlaboratory precision.

In a total of 244 stool samples obtained from 134 healthy controls and 110 IBD patients, fCal was assayed as described in the Clinical evaluation section. The same thawed stool samples were used to measure fCal with three different assays, ELISA, CLIA and turbidimetry, performed simultaneously. The results were compared using Passing-Bablok regression (Supplementary Figure 1 and Table 2), which clearly demonstrated that CLIA assay underestimated fCal with respect to ELISA and turbidimetric assays, and that the latter provided a higher dynamic range of values.

\section{Biological fCal variability}

To complete the assessment of overall fCal variability, biological variability was evaluated. Stool extraction and fCal determination were performed with the three assays in parallel batches, all samples being analyzed in duplicate. With the ELISA assay, the results for all samples were within the measurement range, whereas with CLIA and turbidimetric assays, 19 and 9 subjects, respectively, had at least one value below the respective detection limits ( $16.1 \mu \mathrm{g} / \mathrm{g}$ for CLIA and $20 \mu \mathrm{g} / \mathrm{g}$ for turbidimetry). These subjects were excluded from the measurement of biological variability because data below the detection limit cannot be extrapolated and therefore cannot be used to calculate biological variability. Figure 2 illustrates intra- and interindividual fCal variability; each dot 
Table 1: Repeatability and within-laboratory precision of three different fCal assays calculated for low, intermediate and high $\mathrm{fCal}$ values.

\begin{tabular}{llrrr}
\hline Sample value & Method & Mean \pm SD, $\boldsymbol{\mu g} / \mathbf{g}$ & Repeatability CV, \% & Within-laboratory CV, \% \\
\hline Low & ELISA & $234 \pm 18$ & 6.1 & 8.1 \\
& CLIA & $169 \pm 13$ & 7.5 & 7.6 \\
& Turbidimetry & $312 \pm 49$ & 15.7 & 15.6 \\
Intermediate & ELISA & $393 \pm 50$ & 11.6 & 13.0 \\
& CLIA & $213 \pm 24$ & 9.7 & 15.6 \\
& Turbidimetry & $333 \pm 71$ & 14.7 & 16.4 \\
High & ELISA & $655 \pm 305$ & 25.3 & 27.6 \\
& CLIA & $605 \pm 92$ & 9.6 & 11.8 \\
& Turbidimetry & $1003 \pm 143$ & 13.8 & 14.4 \\
\hline
\end{tabular}

Table 2: Methods comparison, fCal was assayed in 244 stool samples with three different assays (ELISA, CLIA and turbidimetry).

\begin{tabular}{llll}
\hline & Intercept $(\mathbf{9 5} \% \mathrm{Cl})$ & Regression coefficient $\mathbf{9 5 \%} \mathrm{Cl})$ & Interpretation \\
\hline CLIA vs. ELISA & $-4.93(-6.36$ to -1.65$)$ & $0.47(0.43$ to 0.49$)$ & Constant and proportional negative bias \\
Turbidimetric vs. ELISA & $-15.46(-22.88$ to -8.95$)$ & $1.13(1.03$ to 1.22$)$ & Constant and proportional positive bias \\
CLIA vs. turbidimetric & $3.92(1.63$ to 4.12$)$ & $0.41(0.38$ to 0.44$)$ & Constant and proportional negative bias \\
\hline
\end{tabular}

The results of Passing-Bablok regression are shown.

ELISA

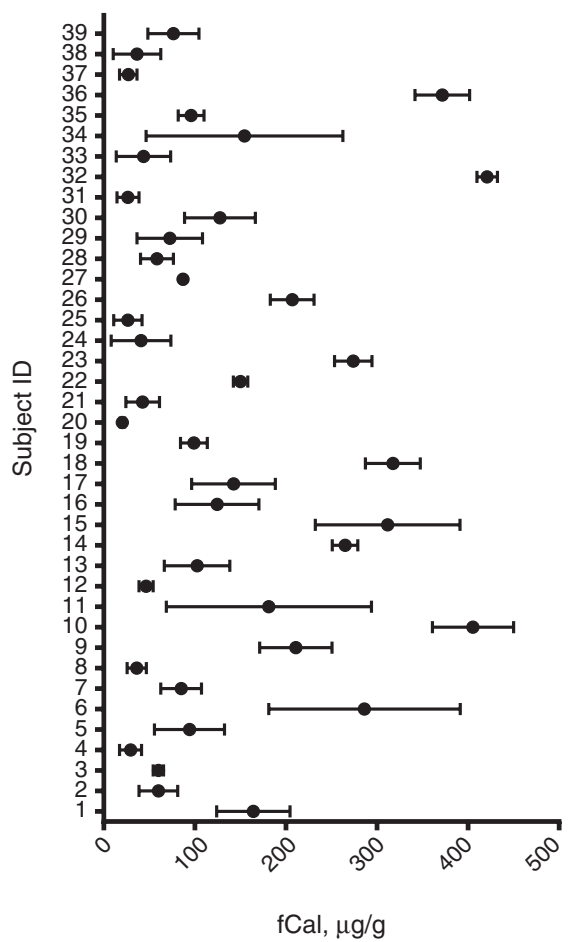

CLIA

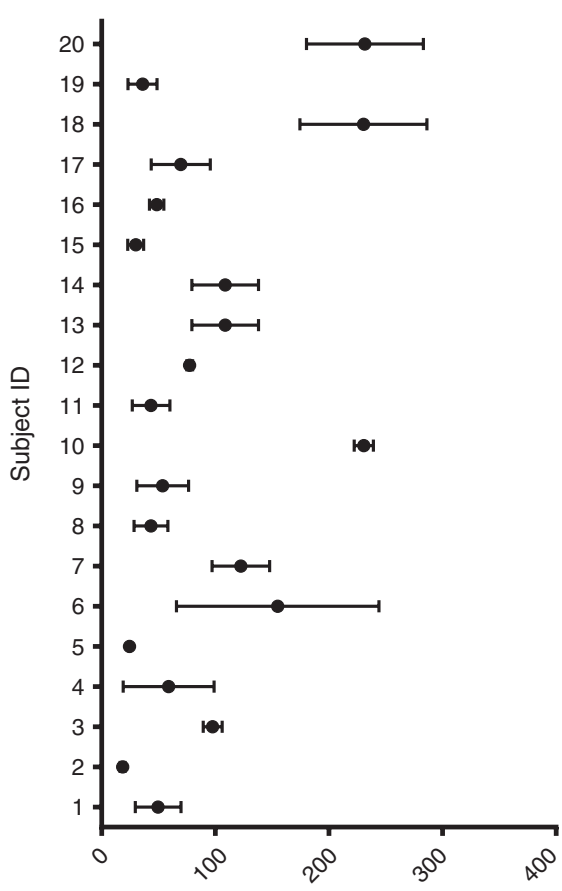

fCal, $\mu \mathrm{g} / \mathrm{g}$
Turbidimetric

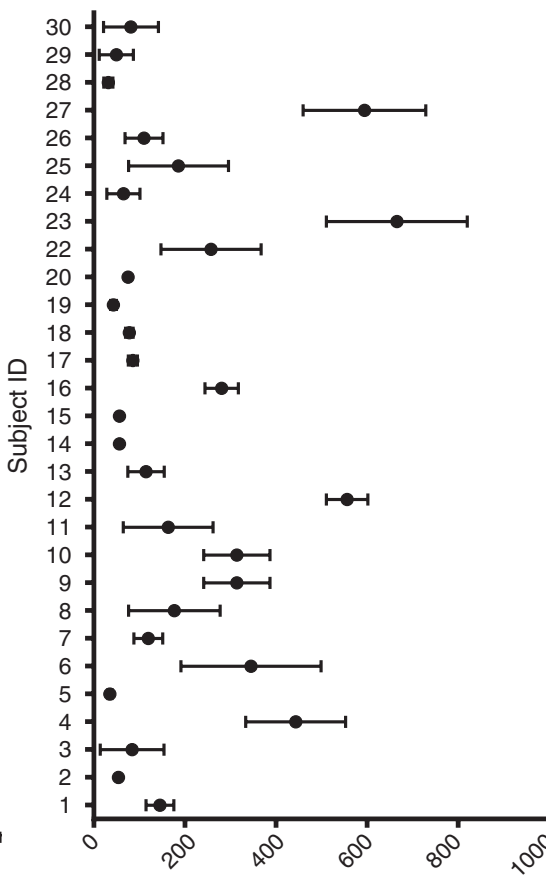

$\mathrm{fCal}, \mu \mathrm{g} / \mathrm{g}$

Figure 2: Intra-individual and inter-individual fCal variability obtained with ELISA, CLIA and turbidimetric assays.

Each point represents the mean value of one subject, and the bars show the corresponding standard deviation.

represents the mean value of a subject, and the lines show the corresponding standard deviation. Table 3 reports the intra- and interindividual biological variation for all methods together with the individuality index and the reference change value. Residual plots were evaluated for homoscedasticity. 
Table 3: fCal biological variation, individuality index and reference change value.

\begin{tabular}{lrrr}
\hline & $\begin{array}{r}\text { fCal } \\
\text { ELISA }\end{array}$ & $\begin{array}{r}\text { fCal } \\
\text { CLIA }\end{array}$ & $\begin{array}{r}\text { fCal } \\
\text { turbidimetry }\end{array}$ \\
\hline Intra-individual (CVi) & $37.7 \%$ & $31.4 \%$ & $32.3 \%$ \\
Inter-individual (CVg) & $78.0 \%$ & $72.1 \%$ & $84.3 \%$ \\
Individuality index (II) & 0.54 & 0.52 & 0.56 \\
Reference change value (RCV) & $118 \%$ & $104 \%$ & $131 \%$ \\
\hline
\end{tabular}

Intra- and interindividual biological variations were calculated by Nested ANOVA according to Fraser et al. [23]. Analytical variability (CVa) value was also obtained from the same analysis. The individuality index was calculated using the following formula: $\left(\mathrm{CV}_{\mathrm{A}}{ }^{2}+\mathrm{CV}_{1}^{2}\right)^{1 / 2} / \mathrm{CV}_{\mathrm{G}}$. The bidirectional reference change value was calculated using the following formula: $1.96 \times 2^{1 / 2} \times\left(\mathrm{CV}_{\mathrm{A}}^{2}+\mathrm{CV}_{1}^{2}\right)^{1 / 2}$.

\section{Clinical evaluation}

fCal was assayed with the three methods in a series of 110 IBD patients, whose clinical characteristics are summarized in Table 4, and in 134 controls. Figure 3 shows the individual fCal results obtained with the three methods, with values for all assays being significantly higher in both CD and UC patients than in controls (Kruskal-Wallis test: $\mathrm{p}<0.0001$ for ELISA, $\mathrm{p}<0.0001$ for CLIA and $\mathrm{p}<0.0001$ for the turbidimetric assay). Supplementary Figure 2 shows the ROC curves of the three methods. The areas under the receiver operating characteristic curves were 0.787 (95\% CI: 0.729-0.844) for ELISA, 0.748 (95\% CI: 0.684-0.812) for CLIA and 0.738 (95\% CI: 0.674-0.801) for turbidimetry. Supplementary Table 3 reports sensitivity, specificity and positive and negative LR for all assays, calculated on the basis of both the manufacturers' recommended cutoff and the best combination between sensitivity and specificity (Youden index).

fCal was correlated with age in controls $(r=0.3735$, $\mathrm{p}<0.0001$ for ELISA, $\mathrm{r}=0.3941, \mathrm{p}<0.0001$ for CLIA and $\mathrm{r}=0.3508, \mathrm{p}<0.0001$ for turbidimetry), but not in IBD patients $(\mathrm{r}=-0.0965, \mathrm{p}=0.3158$ for ELISA, $\mathrm{r}=-0.0612$, $\mathrm{p}=0.5255$ for CLIA and $\mathrm{r}=-0.1058, \mathrm{p}=0.2714$ for turbidimetry). Fifty and 65 years were the age tertiles of controls, who were subdivided accordingly into three groups: $<50$ years, $50-65$ years and $\geq 65$ years. Significantly higher fCal values were found in controls $\geq 65$ years with respect to the other two groups (Kruskal-Wallis test: $p=0.0016$ for ELISA; $\mathrm{p}<0.0001$ for CLIA and turbidimetric assay; Supplementary Figure 3). ROC curves were obtained in subjects $<65$ or $\geq 65$ years of age. In subjects $<65$ years, the areas under the ROC curves were 0.863 (95\% CI: 0.811-0.915) for ELISA, 0.826 (95\% CI: 0.764-0.887) for CLIA and 0.830 (95\% CI: 0.771-0.889) for turbidimetry; in
Table 4: Clinical characteristics of IBD patients.

\begin{tabular}{|c|c|c|}
\hline & $\begin{array}{l}\text { Crohn's } \\
\text { disease } \\
(n=73)\end{array}$ & $\begin{array}{r}\text { Ulcerative } \\
\text { colitis } \\
(n=37)\end{array}$ \\
\hline Gender M/F & $43 / 30$ & $22 / 15$ \\
\hline Age at enrolment years mean \pm SD & $47 \pm 15$ & $50 \pm 17$ \\
\hline Median years of disease duration (range) & $13(0-35)$ & $13(2-33)$ \\
\hline \multicolumn{3}{|l|}{ Concomitant medication } \\
\hline AZA, 6-MP & $11(15 \%)$ & $4(11 \%)$ \\
\hline Mesalamine & $56(77 \%)$ & $26(70 \%)$ \\
\hline MTX & $2(3 \%)$ & $0(0 \%)$ \\
\hline Anti-TNF therapy & $28(38 \%)$ & $11(30 \%)$ \\
\hline Corticosteroids & $2(3 \%)$ & $3(8 \%)$ \\
\hline ASA & $2(3 \%)$ & $4(11 \%)$ \\
\hline \multicolumn{3}{|l|}{ Harvey-Bradshaw Index (HBI) } \\
\hline $\mathrm{HBI} 0$ & 45 & \\
\hline HBI 1 & 9 & \\
\hline $\mathrm{HBI} 2$ & 9 & \\
\hline HBI 3 & 1 & \\
\hline HBI 4 & 4 & \\
\hline HBI 7 & 1 & \\
\hline HBI 8 & 3 & \\
\hline HBI 12 & 1 & \\
\hline \multicolumn{3}{|l|}{ Partial Mayo Score (PMS) ${ }^{a}$} \\
\hline PMS 0 & & 20 \\
\hline PMS 1 & & 3 \\
\hline PMS 2 & & 1 \\
\hline PMS 3 & & 4 \\
\hline PMS 4 & & 2 \\
\hline PMS 5 & & 1 \\
\hline PMS 6 & & 1 \\
\hline PMS 7 & & 1 \\
\hline PMS 8 & & 1 \\
\hline
\end{tabular}

a Not available in 3 patients. AZA, azathioprine; MTX, methotrexate; 6MP, 6-mercaptopurine; TNF, tumor necrosis factor ; ASA, aminosalicylic acid.

subjects $\geq 65$ years, the values were 0.584 ( $95 \%$ CI: 0.399 $0.769), 0.542$ (95\% CI: $0.358-0.726)$ and 0.509 (95\% CI: 0.331-0.687), respectively. The best possible combination between sensitivity and specificity (Youden index) was used to identify the optimal cutoff for subjects younger and older than 65 years. Table 5 shows the corresponding sensitivities, specificities, positive and negative LR.

\section{Discussion}

Currently, fCal is considered the best available biomarker for detecting active intestinal inflammation, and this supports its use for both diagnosing and monitoring IBD [5, 12, 24-26]. Because the positive and negative predictive values of fCal are high for IBD, in the primary care setting, 

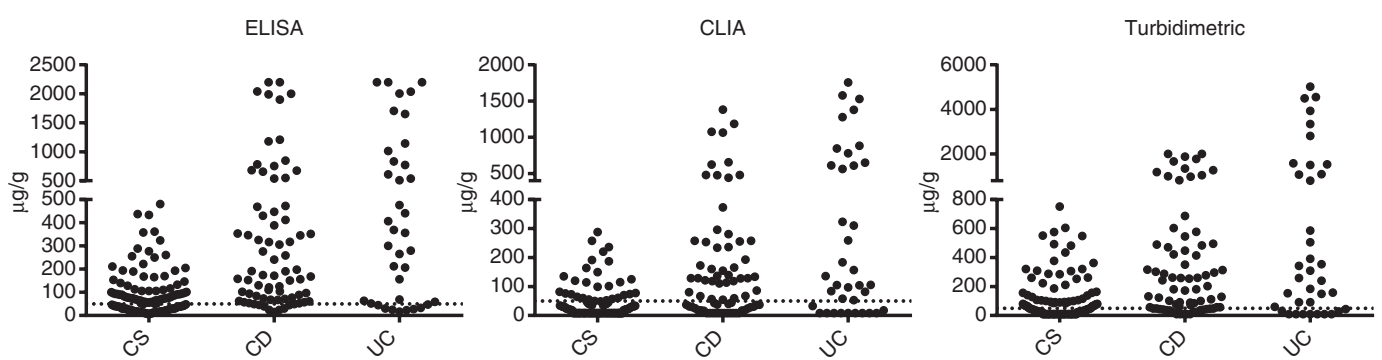

Figure 3: Individual fCal results obtained with ELISA, CLIA and turbidimetric assay in controls (CS) and patients with Crohn's disease (CD) and ulcerative colitis (UC).

The dotted lines show the $50 \mu \mathrm{g} / \mathrm{g}$ cutoff.

Table 5: Age-related fCal cutoff, sensitivity and specificity for different fCal assays.

\begin{tabular}{lll}
\hline & $<65$ years & $\geq 65$ years \\
\hline & ELISA & \\
Cutoff & $120 \mu \mathrm{g} / \mathrm{g}$ & $400 \mu \mathrm{g} / \mathrm{g}$ \\
Sensitivity \% $(95 \% \mathrm{Cl})$ & $68.1(57.5-77.5)$ & $42.1(20.3-66.5)$ \\
Specificity \% $(95 \% \mathrm{Cl})$ & $93.3(86.1-97.5)$ & $95.0(82.3-99.6)$ \\
LR+ & $10.20(4.66-22.40)$ & $6.20(1.84-20.80)$ \\
LR- & $0.34(0.25-0.46)$ & $0.62(0.42-0.92)$ \\
& CLIA & \\
Cutoff & $50 \mu \mathrm{g} / \mathrm{g}$ & $125 \mu \mathrm{g} / \mathrm{g}$ \\
Sensitivity \% $(95 \% \mathrm{Cl})$ & $65.9(55.3-75.5)$ & $47.4(24.4-71.1)$ \\
Specificity \% $(95 \% \mathrm{Cl})$ & $92.2(84.6-96.8)$ & $81.8(67.3-91.8)$ \\
LR+ & $8.48(4.10-17.50)$ & $2.61(1.19-5.72)$ \\
LR- & $0.37(0.27-0.49)$ & $0.64(0.41-1.01)$ \\
& Turbidimetric & \\
Cutoff & $100 \mu \mathrm{g} / \mathrm{g}$ & $580 \mu \mathrm{g} / \mathrm{g}$ \\
Sensitivity \% $(95 \% \mathrm{Cl})$ & $65.9(55.3-75.5)$ & $26.3(9.2-51.2)$ \\
Specificity \% $(95 \% \mathrm{Cl})$ & $87.8(79.2-93.7)$ & $95.0(84.0-89.9)$ \\
LR+ & $5.39(3.04-9.57)$ & $5.79(1.23-27.30)$ \\
LR- & $0.38(0.28-0.52)$ & $0.77(0.58-1.02)$ \\
\hline
\end{tabular}

The cutoffs were calculated by the best combination between sensitivity and specificity (Youden index). Positive (LR+) and negative (LH-) likelihood ratios are also reported.

patients with positive fCal (rule-in) should be referred to the gastroenterologist, unlike patients with negative fCal (rule-out) values $[8,27]$. In this setting, the commonly observed cutoff $(50 \mu \mathrm{g} / \mathrm{g})$ is advocated for distinguishing between patients with and those without intestinal inflammation. In the secondary care setting, fCal determination is of value in monitoring IBD patients because it is predictive of flare-ups [28, 29], and in this setting fCal levels ranging from 250 to $400 \mu \mathrm{g} / \mathrm{g}$ are advocated for distinguishing between IBD patients in remission and those with a relapse [26]. Different thresholds therefore imply different clinical decisions and requires harmonization between different assay types. It is known that the agreement between different fCal ELISA assays is poor, and this scenario might be further complicated by the availability of new fCal assays based on chemiluminescent and turbidimetric revelation systems [13]. We investigated the preanalytical, the analytical and the biological variability of fCal in order to define the reference change value and then compared the clinical utility of three different fCal assays. This enabled us to confirm that different cutoffs should be used for different assays, thus challenging the belief that a common threshold at $50 \mu \mathrm{g} / \mathrm{g}$ is always valid.

Calprotectin was originally described as extremely stable in stool, even when samples were kept at RT for up to 1 week [15]. Another study indicated that fCal is stable for up to 3 days but undergoes a significant decline after 1 week at RT [14]. In our cases, there was a decline in fCal levels within $24 \mathrm{~h}$ of stool collection, whatever the storage temperature. As shown in Figure 1, the magnitude of this early decline varied from $12 \%$, for samples stored at RT, to $13 \%$, for samples stored at $4^{\circ} \mathrm{C}$, without differences in this pattern between IBD and control samples (not shown). This phenomenon, never described elsewhere, might be caused by proteolysis and/or conformational changes interfering with immunoassays. Calprotectin contains 14 potential cleavage sites that might be degraded by trypsin, and this enzyme activity, although very low in feces and characterized by a limited stability, might trigger degradation during the initial hours following stool collection [30]. When stools pass from the intestinal lumen into the collection device, a rapid temperature change may modify the affinity of calprotectin for calcium, zinc and manganese, thus determining conformational molecular changes [31]. Although sample storage at $4^{\circ} \mathrm{C}$ did not prevent the initial fCal decrease, it was safer than RT for storing samples for a few days. In fact, refrigeration, but mainly freezing at $-20^{\circ} \mathrm{C}$ or $-80^{\circ} \mathrm{C}$, counteracted the progressive fCal decline observed when samples were maintained at RT for 4 and 7 days. Because the majority of samples used to study the impact of stool storage on fCal results were obtained 
mainly from IBD patients (14/21, 66\%), we might hypothesize that this phenomenon might depend on the presence in patients' stool of proteases, such as metalloproteinase 9 (MMP9) [32-34], calprotectin being a potential inducers of its expression by inflammatory cells $[35,36]$.

The above results indicate that the best advisable standards for preanalytical fCal handling are RT for very short-term storage (up to $24 \mathrm{~h}$ ), refrigeration for short-term storage (up to $48 \mathrm{~h}$ ) and freezing at $-20^{\circ} \mathrm{C}$ for long-term storage.

The overall precision of the different immunometric assays evaluated in this study was acceptable, the repeatability and the within-laboratory coefficients of variation almost always being lower than $15 \%$ or even lower than $10 \%$, although the ELISA showed some failure for high values, with $25 \% \mathrm{CV}$ for repeatability and $28 \% \mathrm{CV}$ for within-laboratory precision. CLIA assay had the highest, whereas the turbidimetric assay had the lowest, precision across low, intermediate and high results; the precision of ELISA was dependent on values, being high for low and intermediate results, but was less satisfactory for high values. The precision and method comparison studies evidenced a constant and proportional bias between the three assays. In particular, with respect to the ELISA, turbidimetric assay had a positive whereas CLIA had a negative constant and proportional bias. These results probably depend on differences in antibody specificity, and in the dynamic ranges of the three assays, ELISA ranging from 7 to $2100 \mu \mathrm{g} / \mathrm{g}$, CLIA from 16.1 to $3500 \mu \mathrm{g} / \mathrm{g}$ the turbidimetry from 20 to $2058 \mu \mathrm{g} / \mathrm{g}$. Intriguingly, the established $50 \mu \mathrm{g} / \mathrm{g}$ cutoff [5] cannot be applied to any assay before it has been clinically verified. We therefore measured fCal using the three methods in a series of IBD patients and controls to identify the best cutoff based on ROC curve analyses. As expected, the unique $50 \mu \mathrm{g} / \mathrm{g}$ cut off was associated with a very low sensitivity for CLIA (63\%), and with a very low specificity for ELISA (46\%) and for the turbidimetric (55\%) assays. For all assays, the ROC-based cutoff was higher than $50 \mu \mathrm{g} / \mathrm{g}$, namely $150 \mu \mathrm{g} / \mathrm{g}$ for ELISA, $80 \mu \mathrm{g} / \mathrm{g}$ for CLIA and $110 \mu \mathrm{g} / \mathrm{g}$ for turbidimetry. Assay-specific cutoffs were associated with a specificity of $80 \%-90 \%$, but a sensitivity of $60 \%-65 \%$. To improve the clinical interpretation of data and method comparison, we ascertained the sensitivity and specificity of each assay considering cases after they had been subdivided into groups younger and older than 65 years because in agreement with previous findings [37], fCal was confirmed to be age related in the present series of controls. Accordingly, for any assay, the cutoff in older subjects was almost three to four times higher than in the younger group, the sensitivity being higher in younger than older patients. Interestingly, although the performance of the three assays was comparable in the young, the sensitivity of the ELISA assay was greater than that of CLIA and turbidimetry in the elderly patients.

The diagnosis of IBD, a life-threatening disease, calls for close monitoring, based on imaging, endoscopy, histology and laboratory testing for fCal, known to be a relevant predictor of disease activity and relapse [28]. Disease monitoring using fCal might benefit from the knowledge of the fCal reference change value (RCV, i.e. the minimal variation between two consecutive measurements with the same assay that is clinically significant because it is independent from any specific threshold and allows the personalized monitoring of patients) [19]. Essential components for estimating the RCV are analytical and biological variability, although the latter is only partially understood $[14,17]$. In this study, we demonstrated that fCal interindividual biological variability is about twice that of intraindividual biological variability, thus determining a low individuality index and supporting the use of RCV in monitoring programs. RCV ranged from 104\% (CLIA) to $131 \%$ (turbidimetric assay), these differences between assays mainly reflecting variations in the precision of the assays. However, in view of the assay-correlated variability in RCV, we support the general proposal of considering a variation over time of fCal that doubles or halves as clinically significant.

\section{Conclusions}

Overall fCal variability depends on the preanalytical storage temperature, analytical variability of the assay and biological variability. These different factors should be strictly controlled by following standard handling procedures from stool collection to analysis, applying method- and age-specific cutoff to distinguish healthy from diseased subjects and using RCV in monitoring programs. Finally, there is a clear need to develop harmonization programs in order to limit interpretation failures.

Acknowledgments: The authors thank Mrs. Monica Razetti and Cinzia Centobene for their valuable technical help in performing the analyses.

Author contributions: All the authors have accepted responsibility for the entire content of this submitted manuscript and approved submission.

Research funding: University of Padova, Department of Medicine - DIMED: BIRD173078/17.

Employment or leadership: None declared.

Honorarium: None declared. 
Competing interests: The funding organization(s) played no role in the study design; in the collection, analysis, and interpretation of data; in the writing of the report; or in the decision to submit the report for publication.

\section{References}

1. Mowat C, Cole A, Windsor A, Ahmad T, Arnott I, Driscoll R, et al. Guidelines for the management of inflammatory bowel disease in adults. Gut 2011;60:571-607.

2. Sands BE. Biomarkers of inflammation in inflammatory bowel disease. Gastroenterology 2015;149:1275-85.e2.

3. Reese GE, Constantinides VA, Simillis C, Darzi AW, Orchard TR, Fazio VW, et al. Diagnostic precision of anti-Saccharomyces cerevisiae antibodies and perinuclear antineutrophil cytoplasmic antibodies in inflammatory bowel disease. Am J Gastroenterol 2006;101:2410-22.

4. Fengming Y, Jianbing W. Biomarkers of inflammatory bowel disease. Dis Markers 2014;2014:710915.

5. Menees SB, Powell C, Kurlander J, Goel A, Chey WD. A metaanalysis of the utility of $\mathrm{C}$-reactive protein, erythrocyte sedimentation rate, fecal calprotectin, and fecal lactoferrin to exclude inflammatory bowel disease in adults with IBS. Am J Gastroenterol 2015;110:444-54.

6. Lin J-F, Chen J-M, Zuo J-H, Yu A, Xiao ZJ, Deng FH, et al. Metaanalysis: fecal calprotectin for assessment of inflammatory bowel disease activity. Inflamm Bowel Dis 2014;20:1407-15.

7. Waugh N, Cummins E, Royle P, Kandala NB, Shyangdan D, Arasaradnam $\mathrm{R}$, et al. Faecal calprotectin testing for differentiating amongst inflammatory and non-inflammatory bowel diseases: systematic review and economic evaluation. Health Technol Assess 2013;17:xv-xix-1-211. [Epub ahead of print] 24286461.

8. Kok L, Elias SG, Witteman BJ, Goedhard JG, Muris JW, Moons KG, et al. Diagnostic accuracy of point-of-care fecal calprotectin and immunochemical occult blood tests for diagnosis of organic bowel disease in primary care: the cost-effectiveness of a decision rule for abdominal complaints in primary care (CEDAR) study. Clin Chem 2012;58:989-98.

9. Zubin G, Peter L. Predicting endoscopic Crohn's disease activity before and after induction therapy in children: a comprehensive assessment of PCDAI, CRP, and fecal calprotectin. Inflamm Bowel Dis 2015;21:1386-91.

10. Louis E, Mary JY, Massouille GV, Grimaud JC, Bouhnik Y, Laharie $D$, et al. Maintenance of remission among patients with Crohn's disease on antimetabolite therapy after Infliximab therapy is stopped. Gastroenterology 2012;142:63-70.e5.

11. D'Inca R, Caccaro R. Measuring disease activity in Crohn's disease: what is currently available to the clinician. Clin Exp Gastroenterol 2014;7:151-61.

12. Boschetti G, Garnero P, Moussata D, Cuerq C, Préaudat C, Duclaux-Loras R, et al. Accuracies of serum and fecal S100 proteins (calprotectin and calgranulin $C$ ) to predict the response to TNF antagonists in patients with Crohn's disease. Inflamm Bowel Dis 2015;21:331-6.

13. Whitehead SJ, French J, Brookes MJ, Ford C, Gama R. Betweenassay variability of faecal calprotectin enzyme-linked immunosorbent assay kits. Ann Clin Biochem 2013;50:53-61.
14. Lasson A, Stotzer P-O, Öhman L, Isaksson S, Sapnara M, Strid H. The intra-individual variability of faecal calprotectin: a prospective study in patients with active ulcerative colitis. J Crohns Colitis 2015;9:26-32.

15. Røseth AG, Fagerhol MK, Aadland E, Schjønsby H. Assessment of the neutrophil dominating protein calprotectin in feces. A methodologic study. Scand J Gastroenterol 1992;27:793-8.

16. Husebye E, Tøn H, Johne B. Biological variability of fecal calprotectin in patients referred for colonoscopy without colonic inflammation or neoplasm. Am J Gastroenterol 2001;96:2683-7.

17. Du L, Foshaug R, Huang VW, Kroeker KI, Dieleman LA, Halloran $B P$, et al. Within-stool and within-day sample variability of fecal calprotectin in patients with inflammatory bowel disease: a prospective observational study. J Clin Gastroenterol 2018;52:235-40.

18. Calafat M, Cabré E, Mañosa M, Lobatón T, Marín L, Domènech E. High within-day variability of fecal calprotectin levels in patients with active ulcerative colitis: what is the best timing for stool sampling? Inflamm Bowel Dis 2015;21:1072-6.

19. Plebani M. What information on quality specifications should be communicated to clinicians, and how? Clin Chim Acta 2004;346:25-35.

20. De Sloovere MM, De Smet D, Baert FJ, Debrabandere J, Vanpoucke HJ. Analytical and diagnostic performance of two automated fecal calprotectin immunoassays for detection of inflammatory bowel disease. Clin Chem Lab Med 2017;55:1435-46.

21. Kittanakom S, Shajib MS, Garvie K, Turner J, Brooks D, Odeh S, et al. Comparison of fecal calprotectin methods for predicting relapse of pediatric inflammatory bowel disease. Can J Gastroenterol Hepatol 2017;2017:1450970.

22. Clinical and Laboratory Standards Institute (CLSI). User verification of precision and estimation of bias; Approved GuidelineThird Edition. CLSI EP15, Wayne, PA, USA, 2014.

23. Fraser CG, Harris EK. Generation and application of data on biological variation in clinical chemistry. Crit Rev Clin Lab Sci 1989;27:409-37.

24. van Deen WK, van Oijen MG, Myers KD, Centeno A, Howard W, Choi JM, et al. A nationwide 2010-2012 analysis of U.S. health care utilization in inflammatory bowel diseases. Inflamm Bowel Dis 2014;20:1747-53.

25. Ferreiro-Iglesias R, Barreiro-de Acosta M, Lorenzo-Gonzalez A, Dominguez-Muñoz JE. Accuracy of consecutive fecal calprotectin measurements to predict relapse in inflammatory bowel disease patients under maintenance with anti-TNF therapy: a prospective longitudinal cohort study. J Clin Gastroenterol 2018;52:229-34.

26. Heida A, Park KT, van Rheenen PF. Clinical utility of fecal calprotectin monitoring in asymptomatic patients with inflammatory bowel disease: a systematic review and practical guide. Inflamm Bowel Dis 2017;23:894-902.

27. Pavlidis P, Chedgy FJ, Tibble JA. Diagnostic accuracy and clinical application of faecal calprotectin in adult patients presenting with gastrointestinal symptoms in primary care. Scand J Gastroenterol 2013;48:1048-54.

28. Schoepfer AM, Lewis JD. Serial fecal calprotectin measurements to detect endoscopic recurrence in postoperative Crohn's disease: is colonoscopic surveillance no longer needed? Gastroenterology 2015;148:889-92.

29. Bjarnason I. The use of fecal calprotectin in inflammatory bowel disease. Gastroenterol Hepatol (N Y) 2017;13:53-6. 
30. Dumoulin EN, Van Biervliet S, Langlois MR, Delanghe JR. Proteolysis is a confounding factor in the interpretation of faecal calprotectin. Clin Chem Lab Med 2015;53:65-71.

31. Hayden JA, Brophy MB, Cunden LS, Nolan EM. High-affinity manganese coordination by human calprotectin is calciumdependent and requires the histidine-rich site formed at the dimer interface. J Am Chem Soc 2013;135:775-87.

32. Annaházi A, Molnár T, Farkas K, Rosztóczy A, Izbéki F, Gecse K, et al. Fecal MMP-9: a new noninvasive differential diagnostic and activity marker in ulcerative colitis. Inflamm Bowel Dis 2013;19:316-20.

33. Farkas K, Saródi Z, Bálint A, Földesi I, Tiszlavicz L, Szűcs M, et al. The diagnostic value of a new fecal marker, matrix metalloprotease-9, in different types of inflammatory bowel diseases. J Crohns Colitis 2015;9:231-7.

34. Farkas K, Bálint A, Bor R, Földesi I, Szücs M, Nagy F, et al. Faecal matrix metalloprotease-9 is a more sensitive marker for diagnosing pouchitis than faecal calprotectin: results from a pilot study. Expert Rev Gastroenterol Hepatol 2015;9: 387-92.

35. Moz S, Basso D, Padoan A, Bozzato D, Fogar P, Zambon CF, et al. Blood expression of matrix metalloproteinases 8 and 9 and of their inducers $\mathrm{S} 100 \mathrm{~A} 8$ and $\mathrm{S} 100 \mathrm{~A} 9$ supports diagnosis and prognosis of PDAC-associated diabetes mellitus. Clin Chim Acta 2016;456:24-30.

36. Basso D, Bozzato D, Padoan A, Moz S, Zambon CF, Fogar P, et al. Inflammation and pancreatic cancer: molecular and functional interactions between S100A8, S100A9, NT-S100A8 and TGF $\beta 1$. Cell Commun Signal 2014;12:20.

37. Joshi S, Lewis SJ, Creanor S, Ayling RM. Age-related faecal calprotectin, lactoferrin and tumour M2-PK concentrations in healthy volunteers. Ann Clin Biochem 2010;47:259-63.

Supplementary Material: The online version of this article offers supplementary material (https://doi.org/10.1515/cclm-2018-0134). 